\title{
Immediate and long-term effects of opiate antagonists on postictal behaviour following amygdala kindling in the rat
}

\author{
Georgia A. Cottrell ${ }^{1}$ and Béla Bohus ${ }^{2, *}$ \\ ${ }^{I}$ Rudolf Magnus Institute for Pharmacology, University of Utrecht, Utrecht \\ and ${ }^{2}$ Department of Animal Physiology, University of Groningen, Biological Centre, P.O. Box 14, 9750 AA Haren, The Netherlands
}

Received 9 June 1987, accepted 7 July 1987

Male Wistar rats implanted with bipolar electrodes in the amygdaloid complex were kindled. Subcutaneous injection of naloxone or naltrexone in low doses - 0.12 and $0.24 \mathrm{mg} / \mathrm{kg}$, respectively - dramatically reduced the postictal behavioural depression (BD) at 10 or $60 \mathrm{~min}$. Remarkably, the BD was still reduced one day later. It would appear that the brain mechanisms involved in postictal BD use $\mu$-receptors since BD is quite sensitive to low doses of the preferential antagonists naloxone and naltrexone. The long-term effects, the most novel aspect of these studies, are probably related to immediate effects but could be produced through slow genomic processes or alteration of the response to endogenously released enkephalins.

\section{Amygdala kindling; Behavioural depression; Naltrexone; Naloxone; (After-discharge)}

\section{Introduction}

Since the discovery of convulsive properties of endogenous opioid peptides (Urca et al., 1977; Frenk et al., 1978; Henriksen et al., 1978) the possibility has been investigated that they could play a role in epilepsy. Kindling (Goddard et al., 1969) is an experimental model for epilepsy which entails the administration of one low-amperage, short duration electrical stimulation per day to a limbic structure. Kindling is characterized by the gradual lengthening of the evoked after-discharge (AD) with the accompanying appearance of behavioural components such as immobility, wet-dog shakes, head nodding, and finally a tonic-clonic convulsion.

The limbic structure most commonly used for

\footnotetext{
* To whom all correspondence should be addressed: Department of Animal Physiology, University of Groningen, Biological Centre, P.O. Box 14, 9750 AA Haren, The Netherlands.
}

kindling is the amygdala. Amygdala kindling could involve an opioid mechanism. The brain content of endogenous opioids, specifically [Leu $\left.{ }^{5}\right]-$ and $\left[\mathrm{Met}^{5}\right]$ enkephalin, is increased in amygdala-kindled brains (Vindrola et al., 1981). Although it has been reported that ictal events (AD duration, AD threshold, etc.) do not appear to be influenced by opiates such as morphine (Hardy et al., 1980) or opiate antagonists such as naloxone (Corcoran and Wada, 1979; Frenk et al., 1979; Hardy et al., $1980)$ postictal events are affected. Following the termination of a full-blown tonic-clonic convulsion, the animal is temporarily torpid (i.e., behaviourally comatose) with drastically reduced responsiveness to environmental stimuli. This stage is called postictal depression or behavioural depression (BD). Morphine increases the duration of the BD (Frenk et al., 1979; Hardy et al., 1980) whereas naloxone causes a dramatic reduction or complete elimination of the BD (Frenk et al., 1979; Stone et al., 1982; Jarvis and Freeman, 1983). Several investigators have observed this ef- 
fect following 1,2 or $10 \mathrm{mg} / \mathrm{kg}$ i.p. naloxone injected 5-20 min before the kindling session. Naltrexone $(10 \mathrm{mg} / \mathrm{kg}$ i.p., $20 \mathrm{~min}$ previously), another opiate antagonist, is also effective to reduce the BD duration (Stone et al., 1982).

In our studies on the effects of peptides on hippocampus-kindled seizures (Cottrell et al., 1983) and amygdala-kindled seizures (unpublished), we saw that ACTH fragments with partial agonist/antagonist properties for the opiate receptor (Terenius 1978) attenuate the BD at doses of 3 to $100 \mu \mathrm{g} / \mathrm{kg}$, s.c. The antagonistic effect of the peptides - i.e. an antianalgesic action - is, however, rather slight (Gispen et al., 1976). If the attenuation of the BD is due to the antagonistic action of the peptides the opiate antagonists should be effective at much lower doses than those reported previously. We therefore decided to reinvestigate the effects of naloxone and naltrexone on $\mathrm{AD}$ and $\mathrm{BD}$ in amygdala-kindled rats.

\section{Materials and methods}

Thirty-three male Wistar rats were implanted bilaterally in the amygdaloid complex (incisor bar at $0 ; 1.5 \mathrm{~mm}$ posterior to bregma; $\pm 4.4 \mathrm{~mm}$ lateral; $8.3 \mathrm{~mm}$ below dural surface) with bipolar electrodes made of stainless-steel wire $(0.15 \mathrm{~mm})$ insulated except for the tips. The animals were housed individually in a room with a 14:10 h light-dark cycle (lights on from 05:00 to 19:00 h). Testing was done at approximately the same time every day with the whole group being tested between 12:00 and 18:00 h. Following a recovery period of at least 1 week, a standard kindling procedure was initiated that consisted of daily electrical stimulation (individual intensity, $60 \mathrm{~Hz}$, $1 \mathrm{~ms}$ bipolar waves, for $1 \mathrm{~s})$ through 1 electrode. The intensity ranged from 2.25-7.50 $\mathrm{V}$ (mean: 4.0). Amygdala electrical activity was recorded through the contralateral electrode on a Grass model $79 \mathrm{C}$ poly/electroencephalograph. Behavioural measures were recorded simultaneously. Animals were considered fully kindled after they had exhibited convulsions on 4 consecutive days. The threshold current intensity which evoked reliable seizures on consecutive days was then determined and used in subsequent test sessions (for more details, see Cottrell et al., 1983).

Daily injections of saline $(0.5 \mathrm{ml}$, s.c.) were administered until the seizure parameters were stable for each animal. Drug treatment was followed by saline administration until return to baseline values. Naloxone was injected subcutaneously $10 \mathrm{~min}$ and naltrexone $60 \mathrm{~min}$ before a kindling session. The order of naloxone and naltrexone administration and the dosage order were varied across animals but the injection volume $(0.5 \mathrm{ml})$ was always the same. The dose range was based on the effective behavioural doses determined in our laboratory. Not every animal received every treatment. Because of the difference in treatment-kindling interval saline was injected either 10 or $60 \mathrm{~min}$ before a kindling session to serve as control for naloxone and naltrexone, respectively.

Two measures were analysed: the duration of the $A D$ and the duration of the $B D$. The $A D$ was defined as the period of synchronous bursting electrical activity and was measured from the electroencephalographic records. The $\mathrm{BD}$ was defined as the period of behavioral immobility between the end of the AD until the onset of locomotion (i.e. when the animal began walking about the test cage). The durations were expressed in min. Difference scores (drug $\mathrm{AD}$ or $\mathrm{BD}$ - saline $\mathrm{AD}_{0}$ or $\mathrm{BD}_{0}=\Delta$ min score) were calculated for each animal. These scores were always related to the pre-drug saline sessions $\left(\mathrm{AD}_{0}\right.$ or $\left.\mathrm{BD}_{0}\right)$. Difference scores for the post-drug saline session were then also calculated based on the pre-drug saline values.

Statistical analyses were carried out for blocks of difference scores composed of a drug and one to three post-drug saline scores. A parametric t-test for paired samples was used. A P level of 0.05 or less was accepted as showing a significant difference the rats were decapitated at the end of the experiments. The formalinized brains were then processed in standard histological techniques in order to verify the electrode sites.

\section{Results}

Both the stimulating and recording electrodes were dispersed within the amygdaloid complex (A 
4.8 to A 7.0 according to Pellegrino and Cushman (1967)). This complex covers the corticomedial, central, basolateral nuclei and the anterior amygdaloid area. No correlation was seen between electrode site and dose/antagonist effectiveness. The baseline values during the pre-drug saline sessions remained quite constant once the seizure parameters were stabilised for each rat.

Naloxone, injected in doses of 0.24 and 0.12 $\mathrm{mg} / \mathrm{kg} 10 \mathrm{~min}$ before the kindling session was effective to reduce the duration of the $\mathrm{BD}(\mathrm{t}=$ $-3.885, P<0.01$ and $t=-2.349, P<0.05$, re-

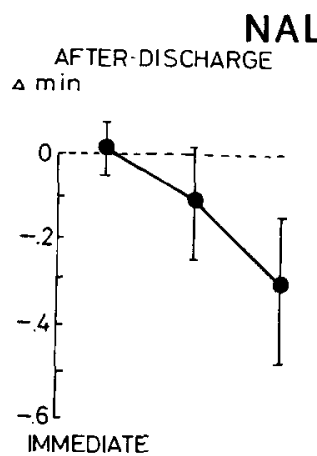

NALOXONE
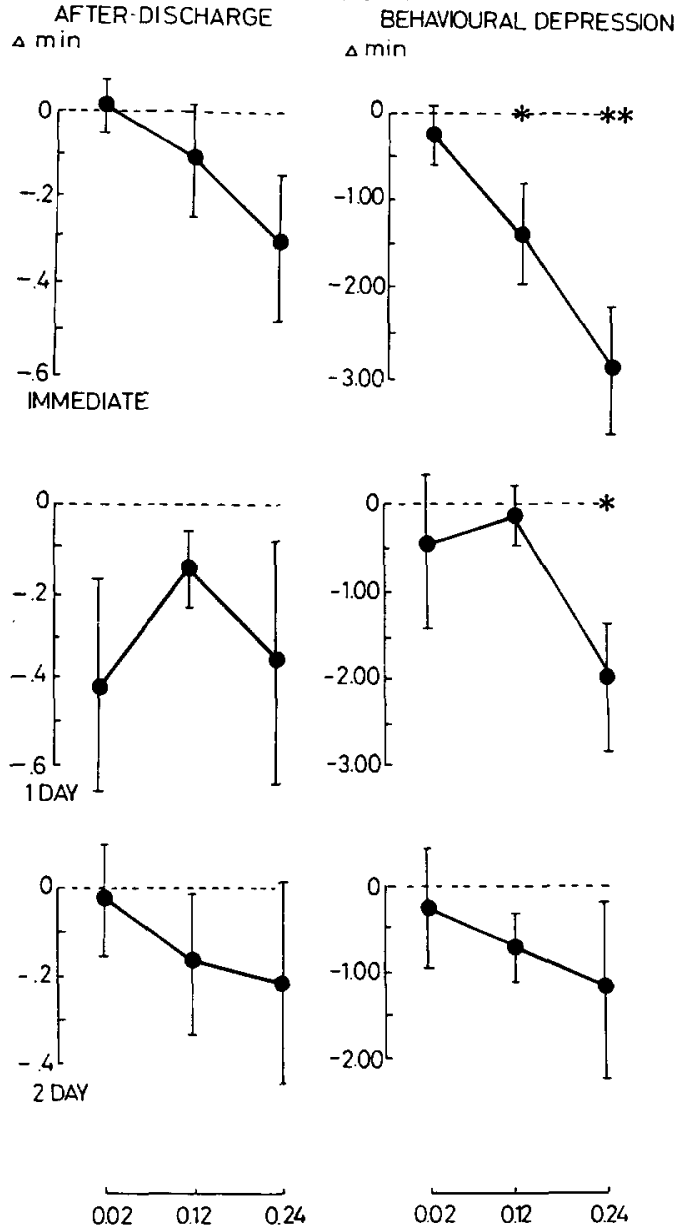

spectively). A dose of $0.002 \mathrm{mg} / \mathrm{kg}$ was ineffective. None of the doses had any significant effect on AD duration (fig. 1, left panel). Naltrexone, injected $1 \mathrm{~h}$ before at a dose of $0.24 \mathrm{mg} / \mathrm{kg}$ was not effective to reduce the duration of the $\mathrm{BD}$ but a dose of $0.48 \mathrm{mg} / \mathrm{kg}$ reduced it significantly $(\mathrm{t}=-2.557, \mathrm{P}<0.05)$. Neither of the doses had any significant effect on the duration of the AD (fig. 1, right panel).

The higher doses of naloxone and naltrexone exerted $24 / 25 \mathrm{~h}$ effects as also shown in fig. 1 (1 day). On the day following opiate antagonist in-
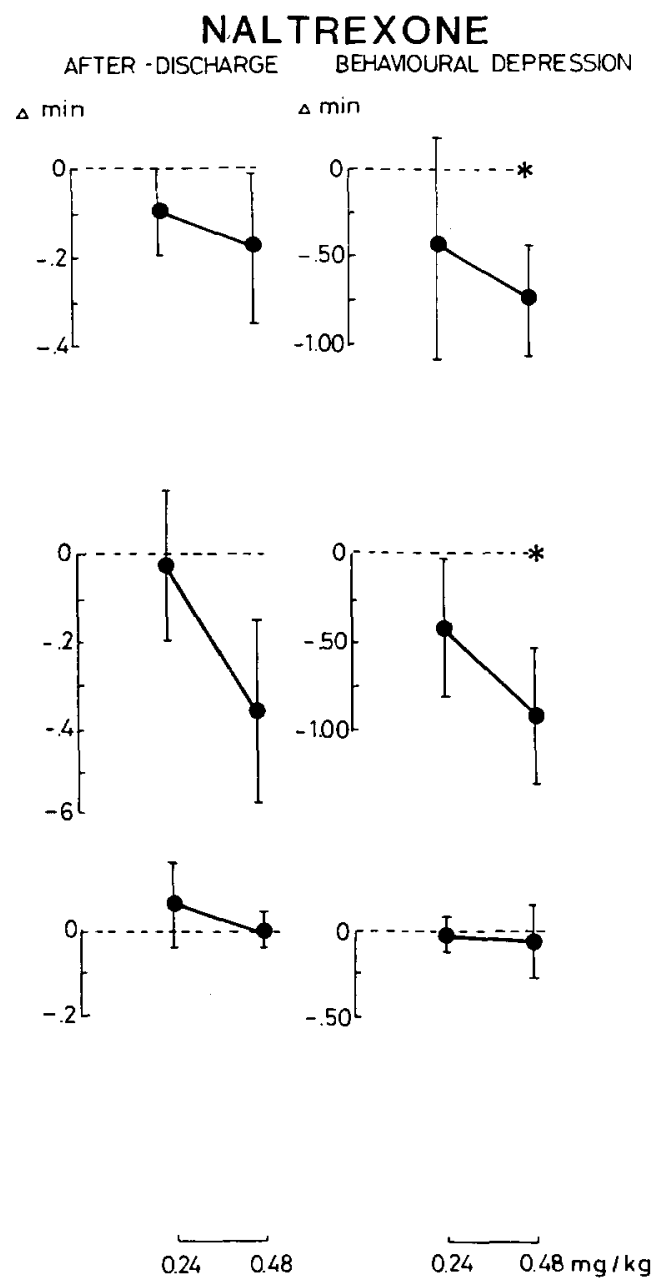

Fig. 1. Naloxone or naltrexone treatments: effects on the duration of after-discharge and behavioural depression in amygdala-kindled rats. Data are plotted as mean $\Delta$ min scores \pm S.E. Asterisks indicate significant group differences from saline baseline at ${ }^{*} P<0.05$ and ${ }^{* *} \mathrm{P}<0.01$ (t-test for paired samples). Left panel: effect of naloxone treatment given $10 \mathrm{~min}, 24 \mathrm{~h}$ or $48 \mathrm{~h}$ before ( $\mathrm{N}=7,10,9$ animals for the $0.02,0.12$ and $0.24 \mathrm{mg} / \mathrm{kg}$ dose groups). Right panel: effect of naltrexone, injected $1 \mathrm{~h}, 25 \mathrm{~h}$ or $49 \mathrm{~h}$ before ( $\mathrm{N}=10$ and 11 animals for 0.24 and $0.48 \mathrm{mg} / \mathrm{kg}$ groups). 
jection, the group injected $24 \mathrm{~h}$ previously with $0.24 \mathrm{mg} / \mathrm{kg}$ naloxone still had a significantly reduced $\mathrm{BD}$ duration $(\mathrm{t}=2.412, \mathrm{P}<0.05)$. A significantly reduced $\mathrm{BD}(\mathrm{t}=-2.317, \mathrm{P}<0.05)$ was also seen $25 \mathrm{~h}$ following $0.48 \mathrm{mg} / \mathrm{kg}$ naltrexone. The other doses of naloxone and naltrexone had no significant effect on the BD duration in the test 1 day after. There were also no significant effects on $\mathrm{AD}$ duration although the one-day scores were not stable, as evidenced by the size of the standard errors for mean durations.

There was still some variability within the mean $\mathrm{AD}$ and BDs $48 \mathrm{~h}$ after naloxone but they no longer differed significantly from baseline. Both naltrexone groups had returned to baseline $49 \mathrm{~h}$ later (fig. 1, 2 days).

\section{Discussion}

As predicted from the peptide experiments, low doses of naloxone $(0.12$ vs. $1-10 \mathrm{mg} / \mathrm{kg})$ and naltrexone $(0.48$ vs. $10 \mathrm{mg} / \mathrm{kg})$ were effective to reduce the duration of the $\mathrm{BD}$ in amygdala-kindled rats. It was consistent with previous reports (Corcoran and Wada, 1979; Frenkel et al., 1974; Hardy et al., 1980) that neither opiate antagonist had a significant effect on the $A D$ at 10 or $60 \mathrm{~min}$. The fact that the $\mathrm{AD}$ and $\mathrm{BD}$ were not affected similarly reinforces the idea (Caldecott-Hazard et al., 1982; Cottrell et al., 1983) that they are the consequence of separate processes. Further, the fact that the opiate receptor antagonists, especially naloxone, were very potent suggests that $\mu$-opiate receptors are involved in the opiate-dependent $\mathrm{BD}$ (Zukin and Zukin, 1981).

The most novel observation was that the opiate antagonists exerted long-term effects. The BD was still significantly reduced one day after treatment in the higher dose groups. Although the AD was not significantly reduced, fluctuations were observed indicating that the opiate antagonists were exerting long-term effects in some animals. We have observed significant reductions in AD duration $24 \mathrm{~h}$ after naltrexone administration to hippocampus-kindled rats (Cottrell et al., submitted). A higher dose could perhaps have had a significant effect. There is also the possibility that the high sensitivity and the long-term effects that we observed were due to the multiple administration of the two opiate antagonists. It has been shown that e.g., chronic administration of naloxone or naltrexone causes an increase in opiate binding in the brain (Lahti and Collins, 1978; Bardo et al., 1983). However, in these experiments the opiate antagonist was administered continuously for 2-5 weeks. It is unlikely that the intermittent schedule of opiate antagonist administration (no closer than 1 injection every third day) and the low doses used in the present study could increase receptor number. A study that involved acute naloxone administration appears to be in agreement since the increase in opiate receptor number only occurred during the $2 \mathrm{~h}$ period immediately following injection (i.e., when naloxone was still present in vivo; Pert and Snyder, 1976). The fact that we observed no changes in the animals' responses between the beginning and end of the experiment is further support for this suggestion. Also, a long-term (24 h) behavioural effect of naloxone has been reported in an open-field situation in which rats were given only one naloxone $(0.5,1$ or $5 \mathrm{mg} / \mathrm{kg})$ injection (Rodgers, 1982).

The question is how could these long-term effects be exerted? We would like to postulate that the opioid system needs to be 'activated' or 'primed' i.e., the opiate antagonist should interact with the kindling experience which would then permit the long-term changes in the response to subsequent kindling without the actual presence of the antagonist on the receptor. This idea is based on the results of a time course experiment that was part of a series of studies on the effects of opiate antagonists on hippocampus-kindled seizures. We found that naltrexone injection ( $1 \mathrm{~h}$ previously), plus kindling stimulation, exerted effects 1 day later but that naltrexone injection alone (i.e., not followed directly by a kindling stimulation) $22 \mathrm{~h}$ previously had no effect (Cottrell et al., submitted). Increased availability of the antagonists due to increased permeability of the blood-brain barrier following seizures could contribute to the long-term effects. Whether the opiate antagonist itself induces the long-term effects through genomic processes or whether the effects are secondary to a decreased response to en- 
kephalins which are released by kindling and seizures are two of the several possibilities.

Interestingly, thyrotropin-releasing hormone (TRH) and its derivative DN-1417 which show antiepileptic effects in feline amygdaloid kindling preparations induced a long-term elevation of the electroconvulsive threshold in some cats (Sato et al., 1984). This elevation appeared only when a positive anticonvulsant effect was observed. TRH interacts with opioid mechanisms without a direct involvement of opioid receptors (e.g. Taché et al., 1977; Narumi et al., 1983). It is therefore inviting to investigate the exact nature of long-term effects (opiate antagonist, TRH) from the point of view of epilepsy therapy.

\section{Acknowledgements}

G.A.C. was supported by a fellowship from the Medical Research Council of Canada. Her present address is Dept. of Pharmacology, Dalhousie University, Halifax, N.S., Canada. The authors wish to thank Dr. C. Nyakas for his advice and help, Ms. C. Maigret for technical assistance and Mrs. Joke Poelstra-Hiddinga for typing the manuscript. Naloxone and naltrexone were generously provided by Endo (New York).

\section{References}

Bardo, M.T., R.K. Bhatnagar and G.F. Gebhart, 1983, Chronic naltrexone increases opiate binding in brain and produces supersentivity to morphine in the locus coerulus of the rat, Brain Res. 289, 223.

Caldecott-Hazard, S., Y. Shavit, R.F. Ackerman, J. Engel, Jr., R.C.A. Frederickson and J.C. Liebeskind, 1982, Behavioral and electrographic effects of opioids on kindled seizures in rats, Brain Res. 251, 372.

Corcoran, M.E. and J.A. Wada, 1979, Naloxone and the kindling of seizures, Life Sci. 24, 791.

Cottrell, G.A., C. Nyakas, B. Bohus and D. De Wied, 1983, ACTH and MSH reduce the after-discharge and behavioural depression following kindling, in: Integrative Neurohumoral Mechanisms, eds. E. Endröczi, D. De Wied, L. Angelucci and U. Scapagnini (Elsevier, Amsterdam) p. 93.

Frenk, H., G. Urca and J.C. Liebeskind, 1978, Epileptic properties of leucine- and methionine-enkephalin: Comparison with morphine and reversibility by naloxone, Brain Res. $147,327$.

Frenk, H., J. Engel, R.F. Ackerman, Y. Shavit and J.C.
Liebeskind, 1979, Endogenous opioids may mediate postictal behavioral depression in amygdala-kindled rats, Brain Res. 167, 435 .

Gispen, W.H., J. Buitelaar, V.M. Wiegant, L. Terenius and D. De Wied, 1976, Interaction between ACTH fragments, brain opiate receptors and morphine-induced analgesia, European J. Pharmacol. 39, 393.

Goddard, G.V., D.C. McIntyre and K. Leech, 1969, A permanent change in brain function resulting from daily electrical stimulation, Exp. Neurol. 25, 295.

Hardy, C., J. Panksepp, J. Rossie and A.J. Zolovick, 1980, Naloxone facilitates amygdala kindling in rats, Brain Res. 194, 293.

Henriksen, S.J., F.E. Bloom, F. McCoy, N. Long and R. Guillemin, 1978, $\beta$-Endorphin induces nonconvulsive limbic seizures, Proc. Nat. Acad. Sci. U.S.A. 86, 5221.

Jarvis, M.F. and F.G. Freeman, 1983, The effects of naloxone and interstimulus interval on post-ictal depression in kindled seizures, Brain Res. 288, 235.

Lahti, R.A. and J. Collins, 1978, Chronic naloxone results in prolonged increases in opiate binding sites in brain, European J. Pharmacol. 51, 185.

Narumi, S., M. Nagai, M. Mixamoto and Y. Nagawa, 1983, Thyreotropin releasing hormone (TRH) and its analog (DN-1417); interaction with pentobarbital in choline uptake and acetylcholine synthesis of rat brain slices, Life Sci. 32, 1637.

Pellegrino, L.J. and A.J. Cushman, 1967, A Stereotaxic Atlas of the Rat Brain (Appleton-Century-Crofts, New York).

Pert, C.B. and S.H. Snyder, 1976, Opiate receptor binding enhancement by opiate administration in vivo, Biochem. Pharmacol. 25, 847.

Rodgers, R.J., 1982, Delayed effects of naloxone on responsiveness to environmental novelty in rate, Psychopharmacology 78,230 .

Sato, M., K. Morimoto and J.A. Wada, 1984, Antiepileptic effects of thyrotropin-releasing hormone and its new derivative, DN-1417, examined in feline amygdaloid kindling preparation, Epilepsia 25, 537.

Stone, W.S., C.E. Eggleton and R.F. Berman, 1982, Opiate modification of amygdaloid-kindled seizures in rats, Pharmacol. Biochem. Behav. 16, 751.

Taché, Y., M. Lis and R. Collu, 1977, Effects of thyrotropin releasing hormone on behavior and hormonal changes induced by beta-endorphin, Life Sci. 21, 841 .

Terenius, L., 1976, Somatostatin and ACTH are peptides with partial antagonist-like selectivity for opiate receptors, European J. Pharmacol. 38, 211.

Urca, G., H. Frenk, J.C. Liebeskind and A.N. Taylor, 1977, Morphine and enkephalin: analgesic and epileptogenic properties, Science 197, 83.

Vindrola, O., R. Briones, M. Asai and A. Fernández-Guardiola, 1981, Amygdaloid kindling enhances the enkephalin content in the rat brain, Neurosci. Lett. 27, 39.

Zukin, R.S. and S.R. Zukin, 1981, Multiple opiate receptors: Emerging concepts, Life Sci. 29, 2681. 